\title{
Video-assisted thoracoscopic trisegmentectomy and left upper lobectomy provide equivalent survivals for stage IA and IB lung cancer
}

\author{
Harmik J. Soukiasian, MD, Edward Hong, MD, and Robert J. McKenna, Jr, MD
}

\begin{abstract}
Objectives: Despite a trend toward sublobar resections for lung cancers, some question the adequacy of limited resections in the treatment of lung cancer and questions remain about performing these procedures by videoassisted thoracoscopic surgery (VATS). We compared the survival for lung cancers treated with VATS segmentectomy versus VATS lobectomy.
\end{abstract}

Methods: VATS segmentectomy and lobectomy for both malignant and benign lung pathology are reviewed from a single institution.

Results: Between 1998 and 2010, 73 VATS trisegmentectomies were performed in 49 women and 24 men (mean age, 72 years). Diagnoses included primary lung cancer $(91 \%)$, benign disease $(4 \%)$, and metastatic disease $(5 \%)$. Primary lung cancers were $68 \%$ for stage IA, $17 \%$ for stage IB, and $15 \%$ for stage II-IV. Seventy-three left upper lobe (LUL) trisegmentectomies were performed. Mean hospital stay after VATS trisegmentectomy was 3.8 days, versus 5.5 days after VATS LUL lobectomy $(P=.0736)$. Complication rates for trisegmentectomy group $(37 \%)$ and lobectomy $(17 \% ; P>.05)$ were not statistically different. Survival after VATS trisegmentectomy and LUL lobectomy for either stage IA lung cancer or stage IB lung cancer was not statistically significant.

Conclusions: Segmentectomy can be performed by VATS with no greater morbidity and mortality than with VATS lobectomy. LUL trisegmentectomy provides the same survival as lobectomy for stage IA and IB tumors. Our experience supports the use of lingular-sparing trisegmentectomy in the treatment of stage IA and IB lung cancer. (J Thorac Cardiovasc Surg 2012;144:S23-6)

Anatomic lung resection for lung cancer has traditionally involved lobectomy and node dissection. ${ }^{1}$ The shift to this lesser resection was a natural progression from pneumonectomy, the previous criterion standard for the treatment of lung cancer. As this desire to perform lesser resections while maintaining oncologic principles continues to evolve, surgeons have probed into the use of anatomic segmental resections for small lung cancers $(<2 \mathrm{~cm})^{2,3}$; however, most of these studies have looked at node-negative tumors of stage IA..$^{4-6}$

Additionally, there are newer options to the surgical approach in the performance of anatomic segmentectomy. Video-assisted thoracoscopic surgery (VATS) has presented itself as an alternative approach to the open technique. VATS has been demonstrated to be associated with shorter

From the Division of Thoracic Surgery, Cedars-Sinai Medical Center, Los Angeles, Calif.

Disclosures: Authors have nothing to disclose with regard to commercial support.

Presented at the 3rd International Minimally Invasive Thoracic Surgery Summit,

Boston, Massachusetts, October 7-8, 2011.

Received for publication Nov 14, 2011; revisions received April 18, 2012; accepted for publication May 18, 2012.

Address for reprints: Robert J. McKenna, Jr, MD, Cedars Sinai Medical Center, Department of Thoracic Surgery, 8635 W Third 975 W Los Angeles, CA 90048

(E-mail: Robert.McKenna@cshs.org).

$0022-5223 / \$ 36.00$

Copyright (C) 2012 by The American Association for Thoracic Surgery

doi:10.1016/j.jtcvs.2012.05.071 stay, faster recovery, and greater ability for the patient to tolerate adjuvant therapy, thus allowing more complete delivery of adjuvant therapy. ${ }^{7,8}$

The literature is not as robust when it comes to stage IB tumors. ${ }^{9}$ Some have postulated that increasing the amount of lung parenchyma taken and thus extending the surgical margins could overcome the increased recurrence risk imposed by the larger tumor size. ${ }^{9,10}$

There remain questions regarding the applicability of segmentectomy in patients with lung cancer. In this article we review our experience with the largest singleinstitution series of VATS anatomic segmentectomy and VATS lobectomies to date and evaluate hospital stay as well as cancer outcomes.

\section{MATERIALS AND METHODS \\ Patients}

Approval for this study was provided by the institutional review board of Cedars-Sinai Medical Center (approval 4267). A retrospective review of a prospectively gathered data base was performed. We identified 149 consecutive VATS segmentectomies performed at our institution from 1998 to 2010. Diagnoses included primary lung cancer, benign disease, and metastatic disease. The primary lung cancers included stage IA, stage IB, and stage II and greater.

We compared the results of 73 VATS trisegmentectomies for stage IA $(\mathrm{n}=45)$ and IB $(\mathrm{n}=11)$ lung cancer at our institution with 266 VATS left upper lobe (LUL) lobectomies for stage IA $(n=105)$ and IB $(n=73)$ lung cancer performed during the same period at our institution. 


\section{Operative Technique}

Under single-lung anesthesia, the VATS lobectomies and segmentectomies were anatomic dissections with individual ligation of the vessels and bronchi. A 5-mm trocar for the 5-mm, 30 thoracoscope was placed through the 8th intercostal space in the midaxillary line. A 2-cm incision was made in the 6th intercostal space in the midclavicular line. A utility incision was made directly lateral from the vein for upper and middle lobectomies, or 1 intercostal space lower for lower lobectomies. This incision started on the anterior border of the latissimus muscle and extended anteriorly for 4 to $6 \mathrm{~cm}$. In some cases, another $1-\mathrm{cm}$ incision was made in the auscultatory triangle. ${ }^{11}$ Lymph nodes were either sampled or dissected.

\section{Statistical Analysis}

Segmentectomy and lobectomy cohorts were compared with respect to clinical, pathologic, and demographic findings. The Student $t$ test was used to compare morbidity rates and stays, and $\chi^{2}$ tests were used to calculate probability distributions ( $P$ values). Kaplan-Meier survival curves with log-rank test were used to compare survival distributions between the segmentectomy and lobectomy arms and to detect trends in survival, and the associated $P$ value. Values are mean $\pm \mathrm{SD}$.

\section{RESULTS}

The average age of patients treated with trisegmentectomy was 72 years. Sex distribution was 49 female and 24 male patients.

Mean hospital stay for patients undergoing VATS trisegmentectomy was $3.8 \pm 3.3$ days, versus $5.5 \pm 7.9$ days for VATS LUL lobectomy $(P=.0736)$.

Seventy-three LUL trisegmentectomies were performed. Diagnoses for the trisegmentectomies included primary lung cancer $(91 \% ; 66 / 73)$, benign disease $(4 \% ; 3 / 73)$, and metastatic disease $(5 \%$; 4/73). Of the VATS trisegmentectomies for primary lung cancers, $68 \%(45 / 66)$ were for stage IA disease, $17 \%(11 / 66)$ were for stage IB disease, and $15 \%(10 / 66)$ were for stage II and greater disease.

In the trisegmentectomy group, the complication rate was $37 \%(\mathrm{n}=27)$, versus $17 \%(\mathrm{n}=44)$ for VATS LUL lobectomy $(P>.05)$. There was no statistical difference in overall complication rate between the groups (Table 1).

\section{Survival}

There was no difference in survival between patients undergoing VATS trisegmentectomy and those undergoing LUL lobectomy for either stage IA lung cancer or stage IB lung cancer (Figures 1-3).

\section{DISCUSSION}

There is a long history of segmentectomy for pulmonary disease. Churchill and Belsey ${ }^{12}$ reported performing a segmentectomy for bronchiectasis in 1939, and Jensik and colleagues ${ }^{13}$ reported a 15 -year experience of segmentectomy for lung cancer in 1973. In the 1980s, the Lung Cancer Study Group demonstrated a $20 \%$ better survival for patients who underwent a lobectomy rather than a sublobar resection. ${ }^{1,14}$ Because of this disparity, lobectomy has been adopted as the criterion standard and is the most common
TABLE 1. Comparison of the complications for trisegmentectomies and left upper lobectomies

\begin{tabular}{|c|c|c|c|c|}
\hline \multirow[b]{2}{*}{ Complications } & \multicolumn{2}{|c|}{ Trisegmentectomy } & \multicolumn{2}{|c|}{$\begin{array}{l}\text { Left upper } \\
\text { lobectomy }\end{array}$} \\
\hline & $\mathbf{n}$ & $\%$ & $\mathbf{n}$ & $\%$ \\
\hline Air leak & 10 & 13.7 & 13 & 4.9 \\
\hline Atrial fibrillation & 6 & 8.2 & 9 & 3.4 \\
\hline Urinary retention & 2 & 2.7 & 0 & 0 \\
\hline Perioperative mortality & 1 & 1.4 & 2 & 0.8 \\
\hline Pneumonia & 1 & 1.4 & 2 & 0.8 \\
\hline Subcutaneous emphysema & 1 & 1.4 & 2 & 0.8 \\
\hline Conversion to thoracotomy & 1 & 1.4 & 0 & 0 \\
\hline Recurrent laryngeal nerve damage & 1 & 1.4 & 0 & 0 \\
\hline Pain & 1 & 1.4 & 0 & 0 \\
\hline Wound infection & 1 & 1.4 & 0 & 0 \\
\hline Syncope & 1 & 1.4 & 0 & 0 \\
\hline Bradycardia & 1 & 1.4 & 0 & 0 \\
\hline Bleeding & 0 & 0 & 3 & 1.1 \\
\hline Readmission & 0 & 0 & 4 & 1.5 \\
\hline Empyema & 0 & 0 & 1 & 0.4 \\
\hline Bronchopleural fistula & 0 & 0 & 1 & 0.4 \\
\hline Atelectasis & 0 & 0 & 1 & 0.4 \\
\hline Urinary tract infection & 0 & 0 & 1 & 0.4 \\
\hline Myocardial infarction & 0 & 0 & 2 & 0.8 \\
\hline Pneumothorax & 0 & 0 & 1 & 0.4 \\
\hline Cerebrovascular accident & 0 & 0 & 1 & 0.4 \\
\hline Splenic injury & 0 & 0 & 1 & 0.4 \\
\hline None & 46 & 63 & 222 & 83.5 \\
\hline Total & 73 & 100 & 266 & 100.0 \\
\hline Complication rate & 27 & 37 & 44 & 17 \\
\hline
\end{tabular}

For comparison of overall complication rate, $P>.05$.

option in the surgical treatment of lung cancer. Lesser resections are being revisited, however, as a result of screening and earlier diagnosis, with the finding of smaller and earlier lung tumors. Beginning in the 1990s, reports have suggested that anatomic segmentectomy may result in survival as good as that of lobectomy in the

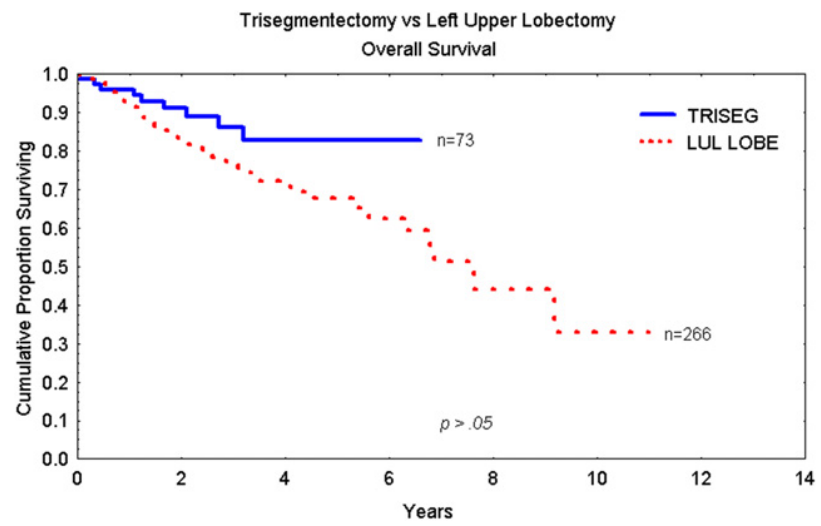

FIGURE 1. The Kaplan-Meier curves compare the overall survivals for patients who underwent trisegmentectomy (TRISEG) and left upper lobectomy ( $L U L L O B E)$. There is no difference in overall survival between the patient populations. 


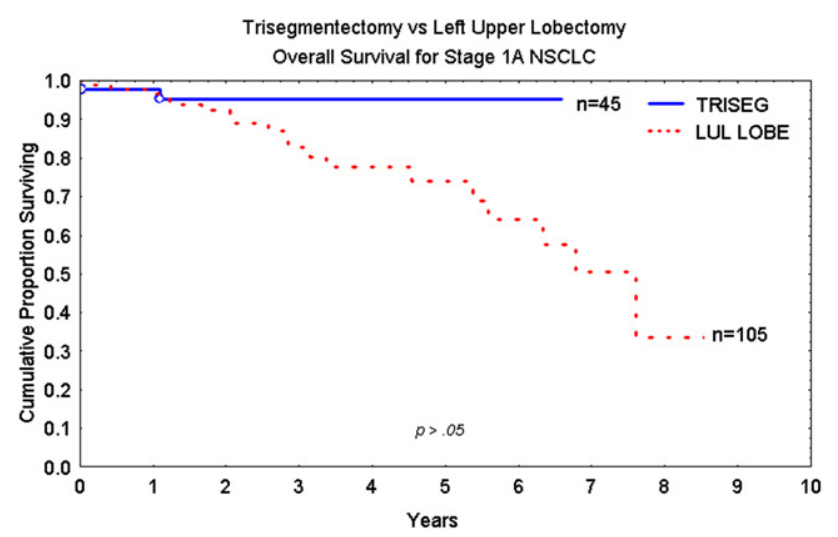

FIGURE 2. The Kaplan-Meier curves compare the overall survivals for patients who underwent trisegmentectomy (TRISEG) and left upper lobectomy ( $L U L L O B E)$ for stage IA lung cancer. There is no difference in survival between trisegmentectomy and left upper lobectomy for stage IA. NSCLC; Non-small cell lung cancer.

treatment of lung cancer, ${ }^{15-17}$ with better functional results. ${ }^{18}$ Additionally, Watanabe and coworkers ${ }^{19}$ showed that a node dissection by VATS is as good as the node dissection performed by thoracotomy.

Minimally invasive (VATS) lobectomy is now well established. Relative to a thoracotomy, a VATS approach to lobectomy has been shown to provide reduced morbidity and mortality, ${ }^{20-22}$ shorter stay, ${ }^{23}$ less pain, ${ }^{24}$ earlier recovery, ${ }^{24,25}$ lower cost,${ }^{26}$ better pulmonary function, ${ }^{27}$ less impact on the immune system, ${ }^{28}$ and a better chance of receiving planned adjuvant chemotherapy. ${ }^{29}$ The significant benefits for VATS were summarized nicely in a metaanalysis by Cheng and colleagues. ${ }^{30}$

With the benefit of lobectomy by VATS compared to thoracotomy firmly established, the question remains, what about VATS segmentectomy?

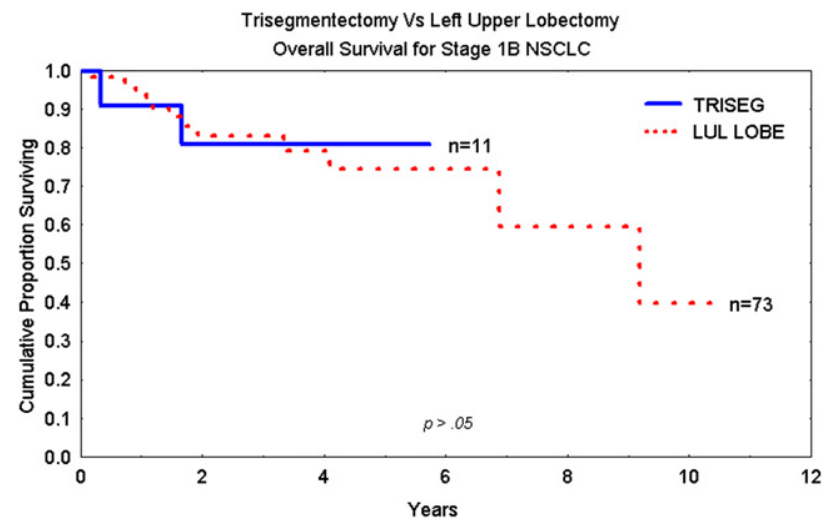

FIGURE 3. The Kaplan-Meier curves compare the overall survivals for patients who underwent trisegmentectomy (TRISEG) and left upper lobectomy ( $L U L L O B E$ ) for stage IB lung cancer. There is no difference in survival between trisegmentectomy and left upper lobectomy for stage IB. NSCLC; Non-small cell lung cancer.
A few small series of VATS segmentectomies have been reported. ${ }^{31-33}$ When comparing 48 VATS and 29 open segmentectomies, Atkins and coworkers ${ }^{31}$ found no difference in morbidity, but hospital stay (mean, 4.3 vs 6.8 days) and mortality ( $0 \%$ vs $6.9 \%$ ) favored VATS. When comparing 104 VATS and 121 open segmentectomies, Schuchert and colleagues ${ }^{32}$ found no difference in morbidity and mortality, but hospital stay favored VATS (median, 5 vs 7 days).

How does VATS segmentectomy compare with VATS lobectomy? In our series, VATS segmentectomy compares favorably with VATS lobectomy.

The biggest concern for a cancer operation is survival rates. In our series, the overall survival was the same for the segmentectomies and the lobectomies. That survival can be affected by many factors, including staging and comorbidities. The comparison of segmentectomy versus lobectomy was most illuminating for LUL cancers. The survival related to the treatment of stage IA and IB tumors was just as good for segmentectomy as for lobectomy.

Our findings are consistent with other published literature. In a comparison of lobectomy with sublobar resection, Warren ${ }^{34}$ showed better survival with lobectomy. There was a significantly higher local recurrence rates for sublobar resections, especially for tumors larger than 3 $\mathrm{cm}$ (T2 tumors). In a comparison of VATS segmentectomy versus open segmentectomy, Atkins and coworkers ${ }^{31}$ found a significantly better survival for VATS; however, the mean tumor size in the VATS cases was $2.1 \mathrm{~cm}$, versus $3.1 \mathrm{~cm}$ in the open cases. This is consistent with the difference in survival by stage, rather than any difference in VATS versus open surgery.

In summary, segmentectomy can be performed by VATS with no more morbidity or mortality than that seen with VATS lobectomy. Transecting parenchyma for the segmentectomy does not translate into a longer stay than after lobectomy. The lingular need not be resected for small apical lung cancers, because LUL trisegmentectomy provides the same survival as lobectomy for stage IA and IB tumors. Our experience supports the use of lingular-sparing trisegmentectomy in the treatment of IA and IB lung cancer.

\section{References}

1. Ginsberg RJ, Rubinstein LV. Randomized trial of lobectomy versus limited resection for T1 N0 non-small cell lung cancer. Lung Cancer Study Group. Ann Thorac Surg. 1995;60:615-23.

2. Schuchert MJ, Pettiford BL, Keeley S, D'Amato TA, Kilic A, Close J, et al. Anatomic segmentectomy in the treatment of stage I non-small cell lung cancer. Ann Thorac Surg. 2007;84:926-33.

3. Okada M, Koike T, Higashiyama M, Yamato Y, Kodama K, Tsubota N. Radical sublobar resection for small-sized non-small cell lung cancer: a multicenter study. J Thorac Cardiovasc Surg. 2006;132:769-75.

4. Tsubota N, Ayabe K, Doi O, Mori T, Namikawa S, Taki T, et al. Ongoing prospective study of segmentectomy for small lung tumors. Ann Thorac Surg. 1998;66:1787-90

5. Nonaka M, Kadokura M, Yamamato S, Kataoka D, Kunimura T, Kushima M, et al. Tumor dimension and prognosis in surgically treated lung cancer: for intentional limited resection. Am J Clin Oncol. 2003;26:499-503. 
6. Koike T, Yamato Y, Yoshiya K, Shimoyama T, Suzuki R. Intentional limited pulmonary resection for peripheral T1 N0 M0 small-sized lung cancer. $J$ Thorac Cardiovasc Surg. 2003;125:924-8.

7. Nicastri DG, Wisnivesky JP, Litle VR, Yun J, Chin C, Dembitzer FR, et al. Thoracoscopic lobectomy: report on safety, discharge independence, pain, and chemotherapy tolerance. J Thorac Cardiovasc Surg. 2008;135:642-7.

8. Petersen RP, Pham D, Burfeind WR, Hanish SI, Toloza EM, Harpole DH Jr, et al. Thoracoscopic lobectomy facilitates the delivery of chemotherapy after resection for lung cancer. Ann Thorac Surg. 2007;83:1245-50.

9. Birdas TJ, Koehler RP, Colonias A, Trombetta M, Maley RH Jr, Landreneau RJ, et al. Sublobar resection with brachytherapy versus lobectomy for stage IB nonsmall cell lung cancer. Ann Thorac Surg. 2006;81:434-9.

10. Yoshikawa K, Tsubota N, Kodama K, Ayabe H, Taki T, Mori T. Prospective study of extended segmentectomy for small lung tumors: the final report. Ann Thorac Surg. 2002;73:1055-9.

11. McKenna RJ Jr. VATS lobectomy with mediastinal lymph node sampling or dissection. Chest Surg Clin North Am. 1995;4:223-32.

12. Churchill ED, Belsey R. Segmental pneumonectomy in bronchiectasis. Ann Surg. 1939;109:481-99.

13. Jensik RJ, Faber LP, Milloy FJ, Monson DO. Segmental resection for lung cancer: a fifteen-year experience. J Thorac Cardiovasc Surg. 1973;63: 563-72.

14. Kittle CF, Faber LP, Jensik RJ, Warren WH. Pulmonary resection in patients after pneumonectomy. Ann Thorac Surg. 1985;40:294-9.

15. Kodama K, Doi O, Higashiyama M, Yokouchi H. Intentional limited resection for selected patients with T1 N0 M0 non-small cell lung cancer: a single-institution study. J Thorac Cardiovasc Surg. 1997;114:347-53.

16. Martin-Ucar AE, Nakas A, Pilling JE, West KJ, Waller DA. A case-matched study of anatomical segmentectomy versus lobectomy for stage I lung cancer in high-risk patients. Eur J Cardiothorac Surg. 2005;27:675-9.

17. Okada M, Yoshikawa K, Hatta T, Tsubota N. Is segmentectomy with lymph node assessment an alternative to lobectomy for non-small cell lung cancer of $2 \mathrm{~cm}$ or smaller? Ann Thorac Surg. 2001;71:956-61.

18. Harada H, Okada M, Sakamoto T, Matsuoka H, Tsubota N. Functional advantage after radical segmentectomy versus lobectomy for lung cancer. Ann Thorac Surg. 2005;80:2041-5.

19. Watanabe A, Koyanagi T, Ohsawa H, Mawatari T, Nakashima S, Takahashi N, et al. Systematic node dissection by VATS is not inferior to through an open thoracotomy: a comparative clinicopathologic retrospective study. Surgery. 2005;138:510-7.

20. McKenna RJ Jr, Houck W, Fuller CB. Video-assisted thoracic surgery lobectomy: experience with 1,100 cases. Ann Thorac Surg. 2006;81:421-6.
21. Hoksch B, Ablassmaier B, Walter M, Müller JM. [Complication rate after thoracoscopic and conventional lobectomy]. Zentralbl Chir. 2003;128:106-10. German.

22. Onaitis MW, Petersen RP, Balderson SS, Toloza E, Burfeind WR, Harpole DH Jr, et al. Thoracoscopic lobectomy is a safe and versatile procedure: experience with 500 consecutive patients. Ann Surg. 2006;244:420-5.

23. Swanson SJ, Herndon JE 2nd, D'Amico T, Demmy T, McKenna RJ Jr, et al. Video-assisted thoracic surgery lobectomy: report of CALGB 39802-a prospective, multi-institution feasibility study. J Clin Onco. 2007;25:4993-7.

24. Demmy TL, Curtis JJ. Minimally invasive lobectomy directed toward frail and high-risk patients: a case-control study. Ann Thorac Surg. 1999;68: 194-200.

25. McVay CL, Fuller CB, Houck W, McKenna R Jr. VATS anatomic pulmonary resection in octogenarians. Am Surg. 2005;71:791-3.

26. Nakajima J, Takamoto S, Kohno T, Ohtsuka T. Costs of videothoracoscopic surgery versus open resection for patients with of lung carcinoma. Cancer. 2000; 89(11 Suppl):2497-501.

27. Nakata M, Saeki H, Yokoyama N, Kurita A, Takiyama W, Takashima S. Pulmonary function after lobectomy: video-assisted thoracic surgery versus thoracotomy. Ann Thorac Surg. 2000;70:938-41.

28. Walker WS, Leaver HA. Immunologic and stress responses following videoassisted thoracic surgery and open pulmonary lobectomy in early stage lung cancer. Thorac Surg Clin. 2007;17:241-9. ix.

29. Flores RM, Rusch VW. Video-assisted thoracic surgery. In: Wilmore DW, Cheung LY, Harken AH, Holcroft JW, Meakins JL, Soper NJ, eds. ACS Surgery: Principles and Practice. New York, NY: Web MD, Inc; 2003.

30. Cheng D, Downey RJ, Kernstine K, Stanbridge R, Shennib H, Wolf R, et al. Video-assisted thoracic surgery in lung cancer resection: a meta-analysis and systematic review of controlled trials. Innovations (Phila). 2007;2:261-92.

31. Atkins BZ, Harpole DH Jr, Mangum JH, Toloza EM, D'Amico TA, Burfeind WR Jr. Pulmonary segmentectomy or thoracotomy or thoracoscopy: reduced hospital length of stay with a minimally invasive approach. Ann Thorac Surg. 2007;84:1107-13.

32. Schuchert MJ, Pettiford BL, Pennathur A, Abbas G, Awais O, Close J, et al. Anatomic segmentectomy for stage I non-small cell lung cancer: comparison of video-assisted thoracic surgery versus open approach. J Thorac Cardiovasc Surg. 2009;138:1318-25.e1.

33. Ohtsuka T, Nomori H, Horio H, Naruke T, Suemasu K. Is major pulmonary resection by video-assisted thoracic surgery an adequate procedure in clinical stage I lung cancer? Chest. 2004;125:1742-6.

34. Warren W, Faber P. Segmentectomy versus lobectomy in patients with stage I pulmonary carcinoma. J Thorac Cardiovasc Surg. 1994;107:1087-94. 